\title{
TEXTO, FECHA Y CIRCUNSTANCIAS DEL LIBRO DE TODAS LAS COSAS Y OTRAS MUCHAS MAS, DE QUEVEDO ${ }^{1}$
}

El Libro de todas las cosas y otras muchas más se publicó por primera vez en la edición de Juguetes de la niñez y travesuras del ingenio que salió a la luz en Madrid (1631), en la imprenta de la viuda de Alonso Martín. Curiosamente por lo que se refiere a textos quevedianos no se conoce ninguna otra edición anterior ni se conserva ningún manuscrito; $y$, en fin, todas las ediciones posteriores, que son tantas como colecciones, antologías, obras, etc. se han publicado luego de Quevedo, toman como texto el de Juguetes. Ningún problema textual, por tanto, aparentemente.

Sin embargo, ya comienza a ser curiosidad que no tenga problemas textuales; esto es: que no haya tenido trasmisión manuscrita ni haya sido pirateado, cuando esto era lo normal en el caso de Quevedo. Recordemos que incluso obras de redacción tan tardía como el Cuento de Cuentos (1626), que también se integró en Juguetes (1631), no sólo circularon manuscritas, sino que se editaron fraudulentamente, al menos cinco veces antes de 1631, antes de la edición "oficial» de las obras festivas de Quevedo ${ }^{2}$. Es más: Quevedo anunció que se editaba por primera vez

1 Estas líneas son una extensión y profundización de la edición que de este texto y otras obrillas festivas preparé para la editorial Castalia (Madrid, 1981), y que allí no pude tratar minuciosamente por razones de espacio.

2 Existen, en efecto, al menos tres manuscritos, en la Biblioteca de la Real Academia de la Historia (12-5-4 = L. 69), en la Biblioteca Menéndez Pelayo de Santander (ms. 116) y en la Biblioteca del Escorial. Ediciones anteriores a Juguetes aparecieron 
( de nuevo») - y debía estar convencido de ello- en 1629, cuando ya algunos libreros de Gerona, Barcelona, Zaragoza y Valencia se han hecho con una versión manuscrita y la acaban de imprimir o la están imprimiendo. El corto espacio de tiempo que media entre comienzos de 1626 -su estancia en Monzón, en donde redacta el Cuento de Cuentos- y setiembre de 1629 -aprobación de Juguetes - ha servido para disparar la trasmisión, manuscrita e impresa, de uno de sus opúsculos festivos, incluso en contra de la voluntad del autor, que quiere editarlo como nuevo en Juguetes.

Quiere esto decir que el Libro de todas las cosas no presentó una cobertura temporal semejante: no dio tiempo a los amigos para hacerse con una copia ni a los editores para imprimirlo. La razón no puede ser otra sino que fue redactado en fecha muy inmediata a Juguetes (1631).

Pero existe un argumento adicional y me parece que indiscutible que nos puede permitir datar la obra con suma facilidad: los polémicos preliminares de Juguetes. Y conviene ir desbrozando en el confuso catálogo de obras quevedianas estos aspectos básicos, para ordenar poco a poco su producción e identificar sus obras. Sobre el Libro de todas las cosas se han dado, por ejemplo, fechas tan dispares como las que van desde comienzos de siglo a las que lo sitúan hacia 1627, como obra tardía ${ }^{3}$.

La cosa, digo, es bastante sencilla. Según Fernández Guerra, la primera aprobación de Juguetes fue encargada o buscada por el Padre Niseno, enemigo declarado de Quevedo, quien naturalmente informó negativamente. La censura negativa estuvo en manos de Fernández Guerra, según propia confesión, y aunque sea uno de estos muchos documentos extraviados $u$ olvidados luego, no parece correcto desconfiar de un erudito tan concienzudo y honrado como el editor de Quevedo en la Biblioteca de Autores Españoles ${ }^{4}$. El documento no aparecerá luego ni en Astrana ni en Felicidad Buendía, los otros dos editores del corpus total de Quevedo. El polígrafo madrileño tuvo que acudir pues a otro censor, Fray Diego del Campo, quien aprobó el libro el 23 de agosto de 1629. En su aprobación enumera cuidadosamente el contenido, al señalar «los tratados en que está dividido». Y cita todos los tratados excepto el Libro

en Gerona (Gaspar Garrich, 1628), dos en Barcelona (Pedro Lacavallería y Esteban Liberós, ambas de 1629), Zaragoza (Pedro Vergés, 1629) y Valencia (Miguel Sorolla, 1629).

3 E. Merimé, Essai sur la vie et les oeuvres de Francisco de Quevedo (París, 1886), pág. 125. Luis Astrana Martn, ed. de las Obras... Verso (Madrid, Aguilar, 1952, $3 .^{2}$ ed.), XXIV. Nadie ha vuelto a ocuparse de esta cuestión luego.

4 A. Fernández Guerra, ed. de las Obras de don Francisco de Quevedo... (Madrid, 1946, reimpr.), II, págs. $463-78$. 
de todas las cosas y otras muchas más y La aguja de navegar cultos. Me parece evidente que en agosto de 1629 esos dos opúsculos no formaban parte de la edición de Juguetes (1631). En el prólogo del propio Quevedo "a los que han leído y leyeren", sin fecha, vuelve a remachar: "Y porque no padezcan la demasía del hurto que han padecido los demás papeles, saco de nuevo el de La Culta Latiniparla y el Cuento de Cuentos...». Tampoco se citan como novedades las del Libro de todas las cosas y La aguja de navegar cultos. Quiere decir que este prologuillo es de la misma época que la aprobación de Fray Diego del Campo, hacia 1629, cuando además era verdad que el Cuento de Cuentos y La Culta Latiniparla estaban inéditos. Pero entre esta fecha y la de la tasa, fe de erratas y privilegio - enero a mayo de 1631 - van a ocurrir muchas cosas que harán variar la actitud de Quevedo y la estructura de Juguetes. No puedo extenderme analizándolas ${ }^{5}$, además de que constituyen un complejo tema aparte; me limitaré a señalar: la denuncia de Pacheco de Narváez a la Inquisición de todo lo que había publicado Quevedo, la autodenuncia del propio Quevedo al Santo Oficio para protegerse de esa y otras acusaciones similares, la preparación y edición inmediata de un índice de libros prohibidos (el de Antonio Zapata, de 1632). Y como telón de fondo: la polémica situación de Quevedo enzarzado con unos y otros acerca del Patronato de Santiago, de los comentaristas de Góngora y de otros mil asuntos más de detalle, como el de las ediciones piratas de La Politica de Dios (1626) y otras obras.

En estas condiciones, Quevedo retrasa la publicación de Juguetes (1631) y toma una doble determinación: encarga a su amigo Alonso Messía de Leyva revisar y expurgar los textos de Juguetes, y escribe el Libro de todas las cosas y otras muchas más con ánimo de integrarlo en la colección. El prologuillo de su fiel colaborador titulado «Advertencia de las causas desta impresión" y la curiosa nota final de los preliminares, «Discursos que salen en esta impresión, ahora añadidos, que nunca se han impreso", se redactan entonces, probablemente con el libro imprimiéndose o ya impreso ${ }^{6}$. En esa nota aparecen como novedades, ade-

5 Vid. mi "Introducción» a la ed. cit. en nota 1. Los avatares de estos años se discuten desde el punto de vista de su producción literaria en J. O. CRosBY, The Sources of the Text of Quevedo's «Politica de Dios» (Nueva York, 1959). Y H. ETtinghausen, "Quevedo's Respuesta al P. Pineda and the Text of the Politica de Dios», BHS, XLVI (1969), 320-30.

6 Contraviniendo, desde luego, la formulilla de la fe de erratas, en la que se dice que "está conforme a su original». Pero eso no tiene nada de extraño. Cfr. mi Manual de Investigación literaria (Madrid, Gredos, 1981), págs. 297-306. Y lo que dijo el propio Quevedo acerca de estas cuestiones legales, en "Obras de Quevedo en la prisión de San Marcos», HR, L (1982), 159-171. 
más de las que había señalado el censor en 1629, el Libro de todas las cosas y La aguja de navegar cultos, esto es: los dos únicos opúsculos de los que no hay tradición manuscrita ni edición pirata o anónima anterior. Es indudable que fueron redactados, quizá «ad hoc», entre finales de 1629 y setiembre de 1631.

2. Sobre La aguja de navegar cultos podemos decir lo mismo que sobre La Culta Latiniparla. Es cuestión de la que me he ocupado en otro lugar, relacionada con la polémica anticulterana?.

Pero, ¿por qué encajar en Juguetes un opúsculo festivo como el Libro de todas las cosas? Hay que recordar la continuada defensa de Quevedo durante estos años alegando que la mayoría de los opúsculos que corrían manuscritos, y en los que sus detractores veían un motivo de escándalo, no son suyos. Quevedo intenta desentenderse de obras como El Buscón, las Gracias y desgracias del ojo del culo, las Pregmáticas de las hermanitas de pecar, etc. Frente a toda esta tradición, el poeta madrileño opta por una excelente solución: redacta un opúsculo festivo nuevo en el que no se dan las características escandalosas de mezclar lo sagrado y lo profano, ni los pasajes desvergonzados, y lo edita en Juguetes como una muestra de un género que todos sabían había cultivado. Con su inclusión admitía -como no podía ser de otra manera- haberlo hecho; pero con obritas como el Libro de todas las cosas, inocuas y entretenidas, que no daban pie a las acusaciones que venía soportando.

3. De todos modos esto no debe llevarnos a la conclusión apresurada de que esta piececita sea una obra de circunstancias de poco valor. Como en otras ocasiones, Quevedo ataca una moda, literaria, la de los libros enciclopédicos y las misceláneas, que se habían venido desarrollando a partir de estructuras literarias tan conocidas como las del Decamerón y, en la época, la imitación de las sesiones académicas. En su burla hay algo de la jactancia despreciativa del «sabio auténtico» que desdeña Calepinos y Polyantheas -él, que las usó tanto- ${ }^{8}$ o que se aparta de las obras con que el vulgo adquiere una cultura de segunda mano, muy superficial. La moda de los Ramilletes de flores historiales, de los Libros de secretos, etc. estaba inundando Europa ${ }^{9}$.

7 «Texto, fecha y circunstancias de La Culta Latiniparla, de Quevedo», BHi, LXXXIII (1981), 131-43.

8 Recuérdese R. A. del Piero, "Quevedo y la Polyanthea», Hispanófila, IV (1958), 49-55. Sobre este género pueden consultarse las páginas que le dedicó Marcer. BaTAIlloN en el Erasmo y España (Méjico, FCE, 1966, 2.a ed.), y las que, a propósito de Cervantes, ensaya Francisco Márouez Villanueva, Fuentes Literarias cervantinas, Madrid, Gredos, 1977.

9 Cito de propósito dos de los más conocidos: el Ramillete de flores historiales recogido de los más señalados sucesos que ha visto el mundo, desde su creación 
Pero también ataca - $i$ inconscientemente? - el prurito manierista de engrosar las formas o géneros que componen la obra, en detrimento de la estructura única, tal y como la cultivaban a porfía autores de todo tipo, desde Cervantes (primera parte del Quijote), Lope de Vega (El Peregrino en su patria) y Tirso de Molina (Cigarrales de Toledo), hasta una retahíla de seguidores, entre los cuales los novelistas eran auténtica legión. El siguiente eslabón del género lo pondrá el malhadado Montalbán, quien tuvo la desgraciada ocurrencia de, siendo enemigo de Quevedo, imprimir su Para Todos (1632) cuando aún estaba fresca la sátira de Quevedo contra esta moda.

4. El Libro de todas las cosas y otras muchas más fue redactado, por tanto, entre agosto de 1629 y setiembre de 1631, probablemente con la intención expresa de que apareciera en Juguetes como una muestra inocua de los muchos opúsculos festivos suyos que circularon en la época.

Si esto es así, algunas cosas más se podrían ir haciendo para abrirse camino en la selva de obras quevedianas, por lo menos en lo que respecta a relaciones entre sus obras en verso y sus obras en prosa.

En efecto, se dan pasajes poéticos que parecen trasliteraciones del Libro de todas las cosas, o viceversa, y que debieron por tanto ser redactados en fecha muy próxima a la señalada. No se trata de coincidencias tópicas, muy significantes de todos modos, como la crítica al modo de comportamiento de los hidalgos ${ }^{10}$, los poemas satíricos dedicados a ciertas aves ${ }^{11}$, etc. sino de concomitancias flagrantes, como ésta; refiriéndose a médicos:

En los zaguanes de grandes / se apea muy reverendo, / porque piensen que visita / en donde orina con miedo. // Porque en su barrio le estimen, / hace que su mozo mesmo / le llame a gritos de noche / para marqueses diversos...//12.

hasta nuestros días...; Madrid, J. Fernández de Buendía, 1669, 3.a ed. (trad. de Lorenzo Matheud y Sanz), obra del jesuita Juan de Busieres. Y el Libro de los secretos de agricultura, casa de campo y pastoril..., que en la traducción y edición de Miguel Agustín (Zaragoza, Pedro Vergés, 1646) alcanzó su forma completa, después de las muchas ediciones habidas desde 1617. A nivel enciclopédico el género alcanza la envergadura del Magnum theatrum vitae humanae, hoc est: rerum divinarum, humanarumque... (Lyon, Joannis Antonii Huguetan, 1678), de Laurencio Beyerlinck, en 8 vols. Las citas podrían multiplicarse.

10 Lo más cercano con pasajes del Libro, otros del poema n. 736 (Poesía original, ed. Blecua, Barcelona, 1967, 2.a ed.): «Pues lo de ser caballero / no sé cómo me lo niega, / sabiendo que hablo despacio / y que hago mala letra".

11 Los remitidos a don Juan de Sal, en la ed. cit., de Blecua, n. 700.

12 Ed. cit., n. ${ }^{\circ} 735$. Estas concordancias constituyen un curioso arsenal, todavía sin estudiar, en las obras de Quevedo.

LXII, $3.0-4.0-8$ 
Y para acreditarte de que visitas casas de señores, apéate a sus puertas y entra en los zaguanes y orina, y tórnate a poner a caballo, que el que te viere salir no sabe si entras a orinar o no... De noche haz a tus amigos que vengan de rato en rato a llamar a tu puerta en altas voces, para que lo oiga la vecindad: « $\mid \mathrm{Al}$ señor dotor, que lo llama el Duque», «que está mi señora la condesa muriéndose...!* (Libro de Todas las cosas, fol. 124r).

Pero éste es un terreno en el que se necesitan todavía muchos trabajos más de erudición, que conduzcan al establecimiento de un catálogo de fuentes y obras quevedianas.

\author{
Pablo Jauralde Pou \\ Universidad Autónoma de Madrid
}

